\title{
Diagnostic Performance of Multiparametric Magnetic Resonance Imaging and Fusion Targeted Biopsy to Detect Significant Prostate Cancer
}

\author{
MANUELA A. HOFFMANN ${ }^{1,2}$, KASRA TAYMOORIAN $^{3}$, CHRISTIAN RUF $^{4}$, ARND GERHARDS $^{5}$, \\ KARLHEINZ LEYENDECKER ${ }^{6}$, THOMAS STEIN ${ }^{6}$, FRANK M. JAKOBS ${ }^{7}$ and MATHIAS SCHRECKENBERGER ${ }^{1}$ \\ ${ }^{1}$ Department of Nuclear Medicine, Johannes Gutenberg-University, Mainz, Germany; \\ ${ }^{2}$ Bundeswehr Medical Service Headquarters, \\ Supervisory Center for Medical Radiation Protection, Koblenz, Germany; \\ ${ }^{3}$ Praxis Urologie, Koblenz, Germany; \\ ${ }^{4}$ Bundeswehr Central Hospital, Department of Urology, Koblenz, Germany; \\ ${ }^{5}$ Radiologisches Institut Dr. von Essen, Koblenz, Germany; \\ ${ }^{6}$ Urologische Gemeinschaftspraxis, Koblenz, Germany; \\ ${ }^{7}$ German Air Force Center for Aerospace Medicine, Department of Epidemiology, Fürstenfeldbruck, Germany
}

\begin{abstract}
Background/Aim: Multiparametric magnetic resonance imaging combined with ultrasound-fusion-targeted biopsy of the prostate intends to increase diagnostic precision, which has to be clarified. Patients and Methods: We performed multiparametric magnetic resonance imaging followed by ultrasound-fusion-guided perineal biopsy in 99 male patients with elevated prostate-specific-antigen and previous negative standard biopsy-procedures. Results: In 33/99 patients (33\%) no malignancy could be confirmed by histopathology. Low-grade carcinomas (Gleason-Score $6+7 a)$ were found in $42 / 66(64 \%)$ and high-grade carcinomas (Gleason-Score $\geq 7 b$ ) in $24 / 66$ (36\%) men. A high-grade carcinoma corresponded to PI-RADS 4 or 5 (suspected malignancy) in 21/24 cases, which accounted for a sensitivity of $88 \%$ and negative-predictive-value of $85 \%$ $(p=0.002)$. Differentiation between high-/low-grade carcinomas (Gleason-Score $\leq 7$ a vs. $\geq 7 b$ ) by means of PIRADS related to a sensitivity of $88 \%$ and a negativepredictive-value of $70 \%(p=0.74)$. Conclusion: The results support the view that multiparametric magnetic resonance
\end{abstract}

Correspondence to: Manuela A. Hoffmann, Department of Nuclear Medicine, Johannes Gutenberg-University, Langenbeckstraße 1, 55101 Mainz, Germany and Supervisory Center for Medical Radiation Protection, Bundeswehr Medical Service Headquarters, Von-Kuhl-Straße 50, 56070 Koblenz, Germany. Tel/Fax: +49 26189626320, email: manuhoffmann@web.de

Key Words: Magnetic resonance imaging, prostatic neoplasms, diagnostic imaging. imaging/ultrasound-fusion-guided biopsy promotes considerably higher detection rates of clinically relevant prostate malignancies than do conventional diagnostic procedures. With regard to differentiation between high-and low-grade carcinomas, no significant difference was demonstrated.

Diagnosis of prostate cancer is still based on non-specific screening methods, such as prostate-specific antigen (PSA) plasma levels and digital rectal examination. Currently, diagnosis is confirmed by core biopsy guided by transrectal ultrasound (US) guidance, but this may result in failure of carcinoma detection in $20-30 \%$ of cases, or undergrading/underestimation of tumor agressivity, respectively (1-3). A major clinical concern is elevated or rising PSA after negative random core prostate biopsy (4). Further diagnostic steps include alternative tumor markers, such as PCA3, repeated or saturation biopsy and prostatic imaging. For elevated PSA with prior negative biopsies, current guidelines recommend multiparametric magnetic resonance imaging (mpMRI) as superior to other diagnostic tools (1, 5-7). This MRI modification selectively combines T2-weighted MRI features with dynamic contrast enhanced (DCE) and diffusion weighted imaging (DWI).

For clinical communication and data exchange purposes, the prostate imaging reporting and data system (PIRADS/PR) version No. 1 has been introduced in 2012 (8). Within this system, point values are applied for each lesion and method that are summarized and transformed into a 5 digit sum score, ranging between PR 1 in case of a presumed benign, and PR 5 in case of a presumed malignant pathology. 
The introduction of the PR system certainly boosted clinical usage and acceptance of mpMRI, providing a considerable gain in diagnostic precision along an enhanced interreader reliability (9). Recently, in collaboration of ESUR and ACR, an actualized version 2 of the PR system has been presented that is optimized for sensitivity and traceability patterns. This system mainly combines the advantages of T2-weighted and DWI imaging, while MRS is spared and DCE is utilized exclusively for classification of PR 3 lesions in the peripheral zone (10).

The undisputed focus of MRI imaging in cancer diagnostics is detection of clinically relevant malignant tumors, with avoidance of over-diagnosis of non-significant lesions $(1,11,12)$. Technical fusion of MRI and ultrasoundguided biopsy allows for targeted cancer identification without the need of a second MRI procedure, thus promoting better localization of tumor tissue (13).

This study intends to quantify the diagnostic precision of prostate cancer detection in patients with increased PSA and prior negative core biopsy, by use of mpMRI and PR with subsequent US-fusion-guided biopsy. Furthermore, we demonstrate that the results of this approach is predictive of defining the histological aggressivity of the underlying tumor.

\section{Patients and Methods}

Inclusion criteria consisted of all patients of a single urological practice seen between January 2015 and January 2016, with a history of elevated PSA ( $\geq 4.0$, depending on age) and one or more prior negative biopsies within the previous 6-24 months. Patients with a history of specific cancer pretreatment, surgical intervention, or inconspicuous PSA plasma levels were excluded.

In all patients that met criteria, MRI was performed using a 3.0 Tesla scanner (General Electric, 3.0T HDxt, MI, USA) and a body phased-array coil. Radiologic evaluation was performed according to the PR version No. 1. Although the updated PR version No. 2 was available in the second half of 2015, we did not change the version for evaluation reason (to compare data).

All patients underwent a stereotactic, image fusion-guided biopsy of the prostate. The procedure was performed in short-term anesthesia, using the BiopSee ${ }^{\circledR}$ device (MedCom, Inc., Darmstadt, Germany). Prior to tissue sampling, MRI data was transferred to the computing unit of the biopsy device and recorded. Suspicious sites of malignancy were tagged and electronically fused with 3D transrectal ultrasound images obtained previously. Once the images were fused, at minimum two experienced urologists (KT, KL, TS) performed the biopsy using a transperineal approach. First, targeted biopsies of suspicious lesions were obtained (maximum of 4 samples per lesion), followed by a standard core random sampling (total max. 15 samples).

Biopsy specimens were histopathologically evaluated according to the Gleason System (2014 ISUP criteria), and were stratified into low-grade (Gleason-Score $\leq 3+4=7 \mathrm{a}$ ) and high-grade (Gleason-Score $\geq 4+3=7 b$ ), malignancies respectively (14). In cases of confirmed malignancy, we additionally assessed the clinical $\mathrm{T}$ stage (according to the TNM classification system), in addition to a total risk estimate based on ESUR criteria (8) as follows:
Table I. Baseline characteristics and patient outcomes.

\begin{tabular}{|c|c|c|c|}
\hline Age & \multicolumn{3}{|c|}{$\begin{array}{c}66.5 \pm 7,3 \text { years } \\
(49-80 \text { years })\end{array}$} \\
\hline PSA (ng/ml) (n=99) & \multicolumn{3}{|c|}{$\begin{array}{c}9.8 \pm 7.8 \\
(3.0-70.0)\end{array}$} \\
\hline \multicolumn{4}{|l|}{ PSA-category $(n=99)$} \\
\hline $\mathrm{I}(\leq 5 \mathrm{ng} / \mathrm{ml})$ & \multicolumn{3}{|c|}{$21(21.2 \%)$} \\
\hline II $(6-<10 \mathrm{ng} / \mathrm{ml})$ & \multicolumn{3}{|c|}{$54(54.5 \%)$} \\
\hline III $(10-20 \mathrm{ng} / \mathrm{ml})$ & \multicolumn{3}{|c|}{$19(19.2 \%)$} \\
\hline $\mathrm{IV}(>20 \mathrm{ng} / \mathrm{ml})$ & \multicolumn{3}{|c|}{$5(5.1 \%)$} \\
\hline \multicolumn{4}{|l|}{ mpMRI PI-RADS $(\mathrm{n}=99)$} \\
\hline 1 & \multicolumn{3}{|c|}{$3(3.0 \%)$} \\
\hline 2 & \multicolumn{3}{|c|}{$3(3.0 \%)$} \\
\hline 3 & \multicolumn{3}{|c|}{$21(21.2 \%)$} \\
\hline 4 & \multicolumn{3}{|c|}{$27(27.3 \%)$} \\
\hline 5 & \multicolumn{3}{|c|}{$45(45.5 \%)$} \\
\hline \multicolumn{4}{|l|}{ T-classification $(n=66)$} \\
\hline $\mathrm{T} 1 \mathrm{c}$ & \multicolumn{3}{|c|}{$60(90.9 \%)$} \\
\hline $\mathrm{T} 2 \mathrm{c}$ & \multicolumn{3}{|c|}{$6(9.1 \%)$} \\
\hline Low risk & \multicolumn{3}{|c|}{$13(19.7 \%)$} \\
\hline Intermediate risk & \multicolumn{3}{|c|}{$40(60.6 \%)$} \\
\hline High risk & \multicolumn{3}{|c|}{$13(19.7 \%)$} \\
\hline $\begin{array}{l}\text { Gleason-Score (GS) } \\
\text { result of fusion guided biopsy }\end{array}$ & $\begin{array}{l}\text { Total } \\
(\mathrm{n}=99)\end{array}$ & $\begin{array}{l}\mathrm{GS} \geq 6 \\
(\mathrm{n}=66)\end{array}$ & Grading \\
\hline$<6$ & $33(33.3 \%)$ & - & - \\
\hline 6 & $13(13.1 \%)$ & $13(19.7 \%)$ & Low-grade \\
\hline $7 a$ & $29(29.3 \%)$ & $29(43.9 \%)$ & $42(63.7 \%)$ \\
\hline$\overline{7 b}$ & $15(15.2 \%)$ & $15(22.7 \%)$ & High-grade \\
\hline 8 & $4(4.0 \%)$ & $4(6.1 \%)$ & $24(36.3 \%)$ \\
\hline 9 & $5(5.1 \%)$ & $5(7.6 \%)$ & \\
\hline
\end{tabular}

- Low Risk: PSA < $10 \mathrm{ng} / \mathrm{ml}, \mathrm{cT} 1-2 \mathrm{a}$, Gleason $\leq 6$

- Intermediate Risk: PSA 10-20 ng/ml, cT2b/c, Gleason 7a/b

- High Risk: PSA >20 ng/ml, >cT2c, Gleason 8-10

Clinically significant cancer was defined as Gleason-Score (GS) $\geq 7$ b. Descriptive statistics, intercept correlations between PR, categorial data and underlying risk factors were assessed by semiquantitative approaches based on calculation of Spearman's correlation coefficient. Test performance metrics (sensitivity, specificity, negative/positive predictive value) were calculated using Chi-square- and Fisher's exact test.

\section{Results}

A total of 99 patients were included, with a mean age of 66 years (48-80). All patients had at least one prior negative standard core biopsy, and none had undergone pretreatment of prostate carcinoma at any time. The mean baseline PSA plasma level was $9.8 \pm 7.8 \mathrm{ng} / \mathrm{ml}$ (Table I).

MpMRI results indicated that 6 patients $(6 \%)$ had presumed benign disease (PR 1+2), 21 patients $(21 \%)$ had equivical diagnostic findings (PR 3), and the majority of patients $(n=72$, $73 \%$ ) displayed diagnostic findings suggestive for malignancy 
a

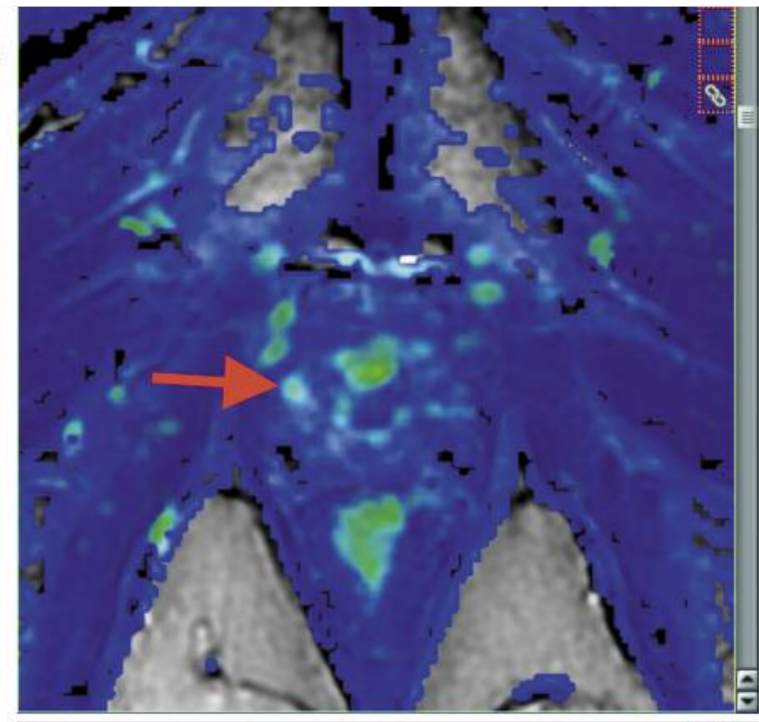

C

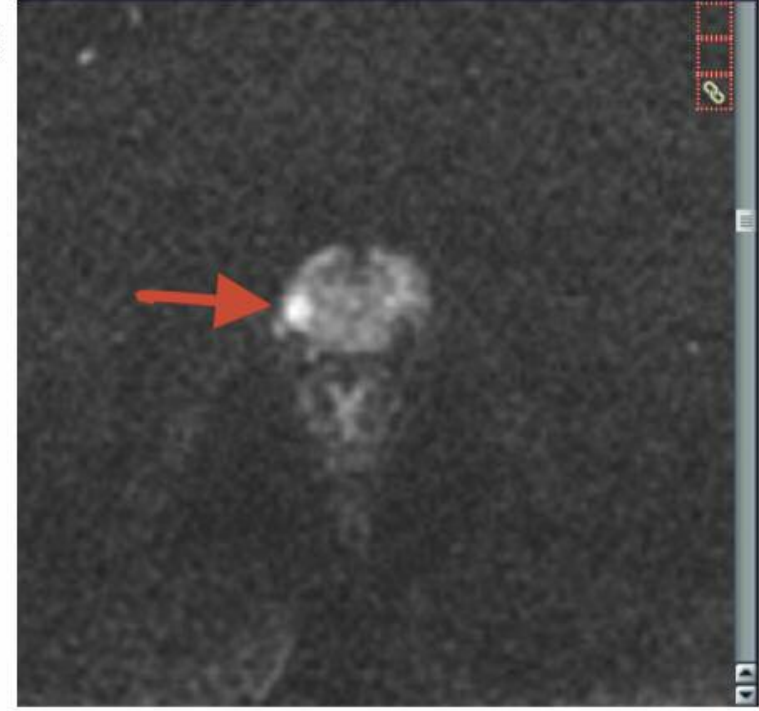

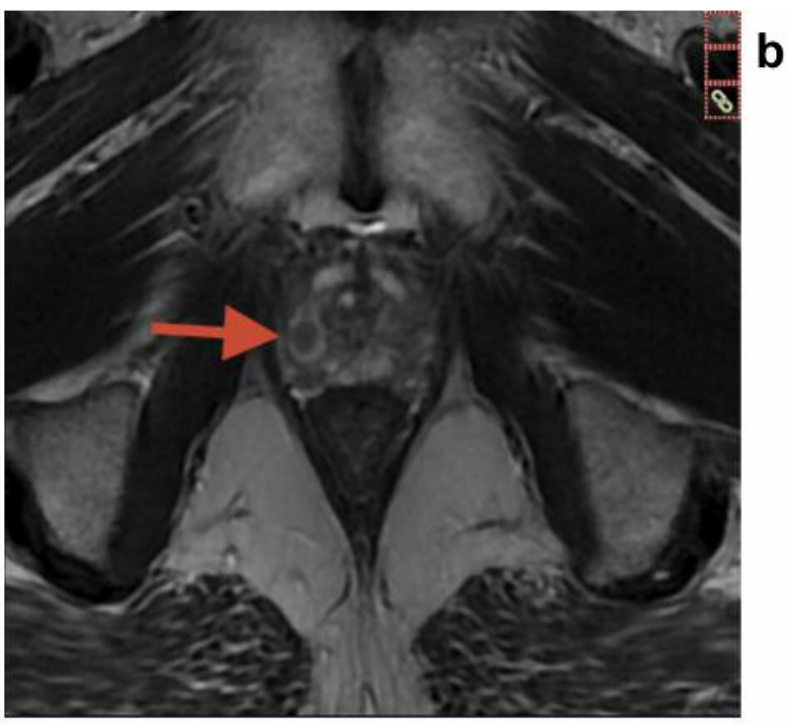

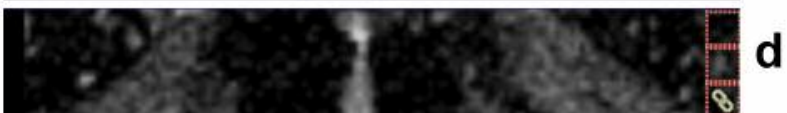

d

\section{b}

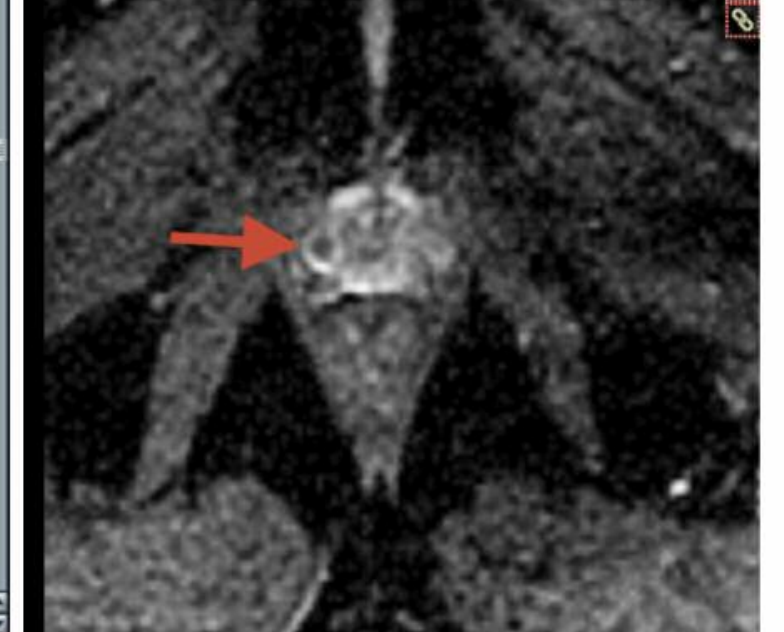

Figure 1. Prostate mpMRI from patient (PR 5) with biopsy confirmed high-grade carcinoma $(G S \geq 7 b)$. The conspicuous lesion, seen in the peripheral zone of the prostate gland, shows an asymmetric hyperperfusion on DCE (a), a low signal intensity focus on axial T2-weighted imaging (b), a focus of high signal on DWI (c) and a focal area of reduced $A D C(d)$.

(PR 4+5) (Figure 1 and Table I). Due to continuously rising PSA-levels, all 27 patients with $\mathrm{PR}<4$ also underwent biopsy.

Histopathological examination following targeted stereotactic biopsy revealed no signs of malignancy in specimens of 33 patients (33\%) (Table II). The respective changes in these patients detected by mpMRI were prostatitis or benign prostate hyperplasia, confirmed by histopathology.

Of the 66 remaining patients, prostate cancer was diagnosed in the suspicious regions. These were classified according to the GS, which yielded a low-grade carcinoma (GS 6, 7a) in 42 cases $(64 \%)$, and a high-grade carcinoma (GS $\geq 7 \mathrm{~b}$ ) in 24 cases $(36 \%)$. The distribution of GS 6-9 is shown in Table I.
When using clinical staging, GS, and PSA for risk stratification, 13 patients $(20 \%)$ were considered low risk, 40 $(61 \%)$ intermediate and $13(20 \%)$ high risk (Table I).

Suspicious lesions were located in all regions of the prostate, but were most commonly isolated to the peripherical zone (46/99) and transition zone (25/99) (Table III). Of the peripheral zone lesions, 34 cases $(74 \%)$ were low-grade (GS $6+7 \mathrm{a})$, while the remaining 12 cases $(26 \%)$ were high-grade (GS $\geq 7 \mathrm{~b}$ ). The corresponding distribution in the transitional zone was 22 (88\%) low-grade and 3 (12\%) high-grade lesions. Regarding PR, virtually all high-grade malignancies in the peripheral zone had been assessed correctly with PR 5, 
Table II. Frequency distribution of Gleason-Score- and separate PI-RADS-categories

\begin{tabular}{|c|c|c|c|c|c|c|c|c|}
\hline \multicolumn{3}{|c|}{ HISTO } & \multicolumn{6}{|c|}{ Gleason-Score } \\
\hline \multirow{2}{*}{ MRI } & & & \multirow[b]{2}{*}{$<6$} & \multicolumn{2}{|c|}{ Low-grade carcinoma } & \multicolumn{3}{|c|}{ High-grade carcinoma } \\
\hline & & & & 6 & $7 \mathrm{a}$ & $7 \mathrm{~b}$ & 8 & 9 \\
\hline \multirow{5}{*}{ PI-RADS } & Carcinoma (-) & 1 & 2 & 0 & 0 & 1 & 0 & 0 \\
\hline & & 2 & 2 & 0 & 1 & 0 & 0 & 0 \\
\hline & Carcinoma (+) & 3 & 13 & 1 & 5 & 1 & 1 & 0 \\
\hline & & 4 & 8 & 7 & 9 & 1 & 1 & 1 \\
\hline & & 5 & 8 & 5 & 14 & 12 & 2 & 4 \\
\hline
\end{tabular}

Table III. PI-RADS Score in comparison with Gleason-Score (GS) considering lesions of the peripheral or transitional zone.

\begin{tabular}{|c|c|c|c|c|c|c|}
\hline \multirow[b]{2}{*}{ PI-RADS } & \multicolumn{3}{|c|}{ Peripheral zone } & \multicolumn{3}{|c|}{ Transitional zone } \\
\hline & GS $6,7 \mathrm{a}$ & $\mathrm{GS} \geq 7 \mathrm{~b}$ & Total & GS $6,7 \mathrm{a}$ & $\mathrm{GS} \geq 7 \mathrm{~b}$ & Tota \\
\hline 1 & 0 & 0 & 0 & 0 & 0 & 0 \\
\hline 2 & $1(100 \%)$ & 0 & 1 & $2(100 \%)$ & 0 & 2 \\
\hline 3 & $8(100 \%)$ & 0 & 8 & $7(87.5 \%)$ & $1(12.5 \%)$ & 8 \\
\hline 4 & $11(100 \%)$ & 0 & 11 & $9(100 \%)$ & 0 & 9 \\
\hline 5 & $14(53.8 \%)$ & $12(46.2 \%)$ & 26 & $4(66.7 \%)$ & $2(33.3 \%)$ & 6 \\
\hline total & $34(73.9 \%)$ & $12(26.1 \%)$ & 46 & $22(88.0 \%)$ & $3(12.0 \%)$ & 25 \\
\hline
\end{tabular}

whereas in the transitional zone 1 of 3 cases had been classified incorrectly with PR 3. MpMRI with US-fusionguided biopsy demonstrated a sensitivity of $85 \%$ with a negative-predictive-value (NPV) of $63 \%(p<0.001)$ to detect prostate cancer (GS 6-9) (Tables II and IV).

Among the 24 patients with high-grade carcinoma (GS $\geq 7 \mathrm{~b}$ ) mpMRI showed highly suspicious lesions (PR 4 or 5 ) in 21 cases $(88 \%)$, which related to a sensitivity of $88 \%$ and a NPV of $85 \%(p=0.002)$.

The proportion of corresponding results in mpMRI (PR 4$5)$, when a low-grade carcinoma had been detected, was $35 / 42(83 \%)$ with a NPV of $71 \%(p<0.001)$.

The overall sensitivity for mpMRI to differentiate between low- and high-grade lesion differentiation (GS $\leq 7 \mathrm{a} v s . \geq 7 \mathrm{~b})$ via PR was $88 \%$, with a NPV of $70 \%$ ( $p=0.74$; Fisher's exact test). The correlation analysis showed that GS also increased with increasing $\mathrm{PR}$, but this relationship was not statistically significant $(\mathrm{R}=0.22)$.

\section{Discussion}

Prostate cancer represents the most frequent cancer, and the third most common cause of cancer-related deaths in males in Germany (15), thus posing a considerable challenge in morbidity and mortality handling in society. More than 60,000 patients are newly diagnosed per year, and 12,000 men will die of the disease. Considering increased life exspectancy, and the fact that treatment is most effective when applied at very early states, early and precise diagnosis is essential.

However, screening for prostate cancer remains controversial. While PSA has a low sensitivity and specificity, DRE has a low PPV and a high inter-observer variability, resulting in overdiagnosing and overtreatment induced by false-positive findings. Similarly, studies have shown that TRUS-guided biopsy fails to detect cancer in about $20-30 \%$ of cases when present, and underdiagnoses the disease in about $25-40 \%$ of cases $(2,3,16-18)$.

It has been shown that up to $40 \%$ of malignancies, initially classified low-risk by means of GS, were upstaged and the patients finally underwent prostatectomy (19). Given the fact that $70-80 \%$ of primary biopsies are negative, it remains unclear whether these are truely negative, or simply limitations of TRUS or PSA and DRE or both (20). The ultimate goal of prostate cancer screening will be to differentiate between clinically significant cancers requiring immediate intervention, and low-risk cancers that can be managed by watchful waiting as a preliminary approach. 
Table IV. Diagnostic performance of mpMRI/US-fusion biopsy (Chi-square test ${ }^{1}$, Fisher's exact test ${ }^{2}$ ).

\begin{tabular}{lcccc}
\hline $\begin{array}{l}\text { Carcinoma- } \\
\text { detection }\end{array}$ & $\begin{array}{c}\text { Carcinoma } \\
(\mathrm{GS} \geq 6)\end{array}$ & $\begin{array}{c}\text { Low-Grade } \\
(\mathrm{GS} \mathrm{6+7a})\end{array}$ & $\begin{array}{c}\text { High-Grade } \\
(\mathrm{GS} \mathrm{7b}+8+9)\end{array}$ & $\begin{array}{c}\text { High- vs. Low- } \\
\text { Grade }\end{array}$ \\
\hline Sensitivity & $84.8 \%$ & $83.3 \%$ & $87.5 \%$ & $87.5 \%$ \\
Specificity & $51.5 \%$ & $51.5 \%$ & $51.5 \%$ & $16.7 \%$ \\
PPV & $77.8 \%$ & $68.6 \%$ & $56.8 \%$ & $37.5 \%$ \\
NPV & $63.0 \%$ & $70.8 \%$ & $85.0 \%$ & $70.0 \%$ \\
Test-value & 14.6671 & 10.3141 & $9.286^{1}$ & $9.286^{2}$ \\
$p$-Value & $<0.001$ & $<0.001$ & 0.002 & 0.740 \\
\hline
\end{tabular}

Recent advances in mpMRI have considerably expanded diagnostic options in prostate cancer management (21-23). This can be used to identify critical tissue alterations for biopsy purposes, thus supporting accurate grading and staging, e.g. by means of PR and GS, as shown in tables II, III and IV. In our study $73 \%$ of PR 4 or 5 alterations were identified by use of this approach, indicating that approximately $75 \%$ of patients displayed suspicious lesions despite previous negative core biopsies.

In this study, only $30 \%$ of biopsies were negative, and most likely, other reasons (inflammatory disease and/or benign prostate hyperplasia) accounted for increased PSA levels. In the remaining $70 \%$ of our study population, prostate cancer was histologically-proven in the targeted lesions only, and not on random sampling. Stratification by tumor grade yielded $2 / 3$ low-grade carcinoma (GS $\leq 7 \mathrm{a}$ ), versus $1 / 3$ of patients high-grade carcinoma ( $G S \geq 7 b$ ), the latter requiring immediate intervention. While these results are in accordance to the results of other authors (24), it has to be noted that not every cancer will be detected by mpMRI. Recent studies $(25,26)$ indicate a false negative rate between $30 \%$ and $50 \%$, however most of these are attributed to GS 6 lesions, and to a lesser extent GS 7 lesions. Sporadically however, even GS 8 malignancies were not seen. But, even if mpMRI fails to detect every tumor, the diagnosis of high-grade tumors seems to be improved by mpMRI $(1,27)$, as $88 \%$ of the patients in our series, diagnosed with high-grade carcinoma, were graded PR 4-5 in mpMRI, and were undetected in previous biopsies. In this study every high-grade carcinoma found in the peripheral zone was detected by mpMRI and classified with PR 4 or 5 .

Ultimately, one of the most fundemental issues in prostate imaging is the ability of the modality to predict histological tumor grading on pathology. In this study malignancy, as confirmed by GS, was detected in $38 \%$ of patients with PR 3, in $70 \%$ with PR 4 and in $82 \%$ with PR 5. Interestingly however, 2 of 6 patients with PR 1 or 2 lesion were also found to harbour cancer, and one of these was even a high-grade tumor. Two out of three cases with PR 1-2 had no malignancy, while $1 / 3$ of cases were classified with GS $7 a-7 b$. The probability of these $33 \%$ (1 patient each) was almost expectable in our collective. In our study, 3/21 high-grade lesions detected with PR 4-5 were GS 8 (14\%) and 5/21 lesions were GS 9 (24\%) (Tables II and IV).

In our study, we calculated a sensitivity of $88 \%$ for identification of high-grade carcinoma, with a NPV of $85 \%$. These results are nearly in accordance with previously published data by Siddiqui et al., who investigated the identifiability of $\leq \mathrm{GS} 7 \mathrm{a}$ and $\geq \mathrm{GS} 7 \mathrm{~b}$ tumors as assessed by standard and fusion biopsy in 1,003 patients (13). The authors showed that use of fusion biopsy resulted in identification of $30 \%$ more high-risk and $17 \%$ less low-risk malignancies when compared to standard biopsy, with a NPV of $70 \%$ and $53 \%$, respectively. Despite the significant benefits of using mpMRI, it is well understood that some clinically significant malignancies might not be detected in imaging (28-30). For this reason, it has been emphasized that supplementary samples should be obtained during the same procedure, and a combination of complementary biopsy methods could impose a new standard of prostate cancer detection (22, 28-33). In our study, cancer was detected within random biopsy in only two patients.

\section{Conclusion}

As imaging technologies improve, screening modalities and clinical surveillance patterns of prostate cancer change. Realtime tumor targeting, image fusion, and risk stratification, using highly specific scoring systems, impose a powerful diagnostic tool at the radiology/pathology interface, that will ultimately help to minimize unnecessary intervention and increase detection rates of clinically significant cancer.

In this study, we present the results from a single center series of 99 patients with increased PSA plasma levels and negative standard biopsy results undergoing mpMRI and USfusion-guided biopsy to detect significant cancer of the prostate. In these selective cases, $67 \%$ were found to harbor malignancy. 
In the present study, prostate carcinoma (GS 6-9) was discovered with a sensitivity of $85 \%$ and a NPV of $63 \%$ $(p<0.001)$, in patients with prior negative conventional biopsies. 24 High-grade carcinomas were identified, along with 42 low-grade lesions. Twenty-one of the high-grade carcinomas identified, corresponded directly with a PR 4-5 lesion on mpMRI, thus resulting in a sensitivity of $88 \%$ and a NPV of $85 \%(p=0.002)$.

In addition, 35 of 42 patients (83\%) with PR 4-5 lesion on mpMRI, were diagnosed as low-grade carcinoma-positive $(p<0.001)$. Malignancy rates as well as high-grade carcinomas were significantly associated with a high PR (4 and 5). Differentiation between high- and low-grade carcinomas (GS $\leq 7 \mathrm{a} v s . \geq 7 \mathrm{~b}$ ) by means of PR related to a sensitivity of $88 \%$ and a NPV of $70 \%(p=0.74)$.

Our results support the view that the mpMRI/US-fusion biopsy promotes considerably higher detection rates of clinically relevant prostate malignancies than do conventional diagnostic procedures. With regard to the differentiation between high- and low-grade carcinomas, no statistical significance could be shown.

\section{Acknowledgements}

The Authors are grateful for the language revision provided by Nicholas Kuntz, MD, Landstuhl Regional Medical Center (LRMC), Urology Clinic.

\section{References}

1 Ahmed HU, El-Shater Bosaily A, Brown LC, Gabe R, Kaplan R, Parmar MK, Collaco-Moraes Y, Ward K, Hindley RG, Freeman A, Kirkham AP, Oldroyd R, Parker C, Emberton M and group Ps: Diagnostic accuracy of multi-parametric MRI and TRUS biopsy in prostate cancer (PROMIS): a paired validating confirmatory study. Lancet 389(10071): 815-822, 2017.

2 Heidegger I, Skradski V, Steiner E, Klocker H, Pichler R, Pircher A, Horninger W and Bektic J: High risk of under-grading and -staging in prostate cancer patients eligible for active surveillance. PLoS One 10(2): e0115537, 2015.

3 Oliveira IS, Pontes-Junior J, Abe DK, Crippa A, Dall'oglio MF, Nesralah AJ, Leite KR, Reis ST and Srougi M: Undergrading and understaging in patients with clinically insignificant prostate cancer who underwent radical prostatectomy. Int Braz J Urol 36(3): 292-299, 2010.

4 Grisanti S, Antonelli A, Buglione M, Almici C, Foroni C, Sodano M, Triggiani L, Greco D, Palumbo C, Marini M, Magrini SM, Berruti A and Simeone C: Analysis of circulating tumor cells in prostate cancer patients at PSA recurrence and review of the literature. Anticancer Res 36(6): 2975-2981, 2016.

5 Mottet N, Bellmunt J, Bolla M, Briers E, Cumberbatch MG, De Santis M, Fossati N, Gross T, Henry AM, Joniau S, Lam TB, Mason MD, Matveev VB, Moldovan PC, van den Bergh RC, Van den Broeck T, van der Poel HG, van der Kwast TH, Rouviere O, Schoots IG, Wiegel T and Cornford P: EAU-ESTRO-SIOG Guidelines on Prostate Cancer. Part 1: Screening, Diagnosis, and Local Treatment with Curative Intent. Eur Urol 71(4): 618-629, 2017.
6 Pepe P, Garufi A, Priolo GD and Pennisi M: Multiparametric MRI/TRUS Fusion Prostate Biopsy: Advantages of a transperineal approach. Anticancer Res 37(6): 3291-3294, 2017.

7 Wu X, Reinikainen P, Kapanen M, Vierikko T, Ryymin P and Kellokumpu-Lehtinen PL: Diffusion-weighted MRI provides a useful biomarker for evaluation of radiotherapy efficacy in patients with prostate cancer. Anticancer Res 37(9): 5027-5032, 2017.

8 Barentsz JO, Richenberg J, Clements R, Choyke P, Verma S, Villeirs G, Rouviere O, Logager V and Futterer JJ: ESUR prostate MR guidelines 2012. Eur Radiol 22(4): 746-757, 2012.

9 Renard-Penna R, Mozer P, Cornud F, Barry-Delongchamps N, Bruguiere E, Portalez D and Malavaud B: Prostate imaging reporting and data system and likert scoring system: multiparametric MR imaging validation study to screen patients for Initial Biopsy. Radiology 275(2): 458-468, 2015.

10 Weinreb JC, Barentsz JO, Choyke PL, Cornud F, Haider MA, Macura KJ, Margolis D, Schnall MD, Shtern F, Tempany CM, Thoeny HC and Verma S: PI-RADS prostate imaging - reporting and data system: 2015, Version 2. Eur Urol 69: 16-40, 2016.

11 Haffner J, Lemaitre L, Puech P, Haber GP, Leroy X, Jones JS and Villers A: Role of magnetic resonance imaging before initial biopsy: comparison of magnetic resonance imaging-targeted and systematic biopsy for significant prostate cancer detection. BJU Int 108(8 Pt 2): E171-178, 2011.

12 Nassiri N, Margolis DJ, Natarajan S, Sharma DS, Huang J, Dorey FJ and Marks LS: Targeted biopsy to detect gleason score upgrading during active surveillance for men with low versus intermediate risk prostate cancer. J Urol 197(3 Pt 1): 632-639, 2017.

13 Siddiqui MM, Rais-Bahrami S, Turkbey B, George AK, Rothwax J, Shakir N, Okoro C, Raskolnikov D, Parnes HL, Linehan WM, Merino MJ, Simon RM, Choyke PL, Wood BJ and Pinto PA: Comparison of MR/ultrasound fusion-guided biopsy with ultrasound-guided biopsy for the diagnosis of prostate cancer. JAMA 313: 390-397, 2015.

14 Junker D, Quentin M, Nagele U, Edlinger M, Richenberg J, Schaefer G, Ladurner M, Jaschke W, Horninger W and Aigner F: Evaluation of the PI-RADS scoring system for mpMRI of the prostate: a whole-mount step-section analysis. World J Urol 33(7): 1023-1030, 2015.

15 Rohde V, Katalinic A and Wasem J: Prostataerkrankungen. Gesundheitsberichterstattung des Bundes. Heft 36. Berlin: RKI, 2007.

16 Djavan B, Ravery V, Zlotta A, Dobronski P, Dobrovits M, Fakhari M, Seitz C, Susani M, Borkowski A, Boccon-Gibod L, Schulman CC and Marberger M: Prospective evaluation of prostate cancer detected on biopsies 1,2, 3 and 4: when should we stop? J Urol 166(5): 1679-1683, 2001.

17 Rapiti E, Schaffar R, Iselin C, Miralbell R, Pelte MF, Weber D, Zanetti R, Neyroud-Caspar I and Bouchardy C: Importance and determinants of Gleason score undergrading on biopsy sample of prostate cancer in a population-based study. BMC Urol 13: 19, 2013.

18 Shapiro RH and Johnstone PA: Risk of Gleason grade inaccuracies in prostate cancer patients eligible for active surveillance. Urology 80(3): 661-666, 2012.

19 Noguchi M, Stamey TA, McNeal JE and Yemoto CM: Relationship between systematic biopsies and histological features of 222 radical prostatectomy specimens: lack of prediction of tumor significance for men with nonpalpable prostate cancer. $\mathrm{J}$ Urol 166(1): 104-109; discussion 109-110, 2001. 
20 Macura KJ: Multiparametric magnetic resonance imaging of the prostate: current status in prostate cancer detection, localization and staging. Semin Roentgenol 43(4): 303-313, 2008.

21 Porpiglia F, Cantiello F, De Luca S, De Pascale A, Manfredi M, Mele F, Bollito E, Cirillo S, Damiano R and Russo F: Multiparametric magnetic resonance imaging and active surveillance: How to better select insignificant prostate cancer? Int J Urol 23(9): 752-757, 2016.

22 Tsivian M, Gupta RT, Tsivian E, Qi P, Mendez MH, Abern MR, Tay KJ and Polascik TJ: Assessing clinically significant prostate cancer: Diagnostic properties of multiparametric magnetic resonance imaging compared to three-dimensional transperineal template mapping histopathology. Int J Urol 24: 137-143, 2017.

23 Ueno Y, Tamada T, Bist V, Reinhold C, Miyake H, Tanaka U, Kitajima K, Sugimura K and Takahashi S: Multiparametric magnetic resonance imaging: Current role in prostate cancer management. Int J Urol 23: 550-557, 2016.

24 Sonn GA, Chang E, Natarajan S, Margolis DJ, Macairan M, Lieu P, Huang J, Dorey FJ, Reiter RE and Marks LS: Value of targeted prostate biopsy using magnetic resonance-ultrasound fusion in men with prior negative biopsy and elevated prostatespecific antigen. Eur Urol 65: 809-815, 2014.

25 Bratan F, Niaf E, Melodelima C, Chesnais AL, Souchon R, Mege-Lechevallier F, Colombel M and Rouviere O: Influence of imaging and histological factors on prostate cancer detection and localisation on multiparametric MRI: a prospective study. Eur Radiol 23(7): 2019-2029, 2013.

26 Rosenkrantz AB, Mendrinos S, Babb JS and Taneja SS: Prostate cancer foci detected on multiparametric magnetic resonance imaging are histologically distinct from those not detected. J Urol 187(6): 2032-2038, 2012.

27 Frye TP, George AK, Kilchevsky A, Maruf M, Siddiqui MM, Kongnyuy M, Muthigi A, Han H, Parnes HL, Merino M, Choyke PL, Turkbey B, Wood B and Pinto PA: Magnetic resonance imaging-transrectal ultrasound guided fusion biopsy to detect progression in patients with existing lesions on active surveillance for low and intermediate risk prostate cancer. J Urol 197(3 Pt 1): 640-646, 2017.

28 Franiel $\mathrm{T}$, Eckardt $\mathrm{N}$, Waginger $\mathrm{M}$ and Horstmann $\mathrm{M}$ : Prostatakarzinom. Radiologe 54: 491-507, 2014.
29 Hansen NL, Kesch C, Barrett T, Koo B, Radtke JP, Bonekamp D, Schlemmer HP, Warren AY, Wieczorek K, Hohenfellner M, Kastner C and Hadaschik B: Multicentre evaluation of targeted and systematic biopsies using magnetic resonance and ultrasound image-fusion guided transperineal prostate biopsy in patients with a previous negative biopsy. BJU Int, 2016. doi: 10.1111/bju.13711

30 Radtke JP, Kuru TH, Boxler S, Alt CD, Popeneciu IV, Huettenbrink C, Klein T, Steinemann S, Bergstraesser C, Roethke M, Roth W, Schlemmer HP, Hohenfellner M and Hadaschik BA: Comparative analysis of transperineal template saturation prostate biopsy versus magnetic resonance imaging targeted biopsy with magnetic resonance imaging-ultrasound fusion guidance. J Urol 193(1): 87-94, 2015.

31 Cash H, Gunzel K, Maxeiner A, Stephan C, Fischer T, Durmus T, Miller K, Asbach P, Haas M and Kempkensteffen C: Prostate cancer detection on transrectal ultrasonography-guided random biopsy despite negative real-time magnetic resonance imaging/ultrasonography fusion-guided targeted biopsy: reasons for targeted biopsy failure. BJU Int 118(1): 35-43, 2016.

32 Shoji S, Hiraiwa S, Ogawa T, Kawakami M, Nakano M, Hashida K, Sato Y, Hasebe T, Uchida T and Tajiri T: Accuracy of realtime magnetic resonance imaging-transrectal ultrasound fusion image-guided transperineal target biopsy with needle tracking with a mechanical position-encoded stepper in detecting significant prostate cancer in biopsy-naive men. Int J Urol 24(4): 288-294, 2017.

33 Zhang Q, Wang W, Zhang B, Shi J, Fu Y, Li D, Guo S, Zhang $\mathrm{S}$, Huang $\mathrm{H}$, Jiang $\mathrm{X}$, Zhou $\mathrm{W}$ and Guo $\mathrm{H}$ : Comparison of freehand transperineal mpMRI/TRUS fusion-guided biopsy with transperineal 12-core systematic biopsy for the diagnosis of prostate cancer: a single-center prospective study in China. Int Urol Nephrol 49: 439-448, 2017.
Received August 30, 2017

Revised September 27, 2017

Accepted September 29, 2017 